\title{
EFEKTIVITAS PEMBERIAN MINYAK ZAITUN TERHADAP RUAM POPOK PADA BALITA USIA 0-36 BULAN
}

\author{
Septian Mixrova Sebayang, Elyani Sembiring \\ Program Studi Ilmu Keperawatan, STIKes Sumatera Utara \\ E-mail : septiansebayang716@gmail.com
}

\begin{abstract}
Diaper dermatitis is one of the most common dermatologic diseases in infants and toddler with high rate of incidence and prevalence. Diaper dermatitis occurs due to poor knowledge of giving care for infant and toddler skin. One of skin care to do infant and toddler with diaper dermatitis is apply olive oil. Olive oil is a herbal remedy with anti-inflammatory, analgesic, anti-microbial and anti-oxidant activities effects. The aim of this study was to analyze the effectiveness of the use olive oil on diaper dermatitis among infants and toddlers aged 0 to 36 months old. This was a quasy experimental study with one group pretest-posttest design with 40 samples in intervention group with total sampling. Subjects were follow up between June until August 2019. Diaper Dermatitis Severity Index Score was used to measure diaper dermatitis. To analyze and compare the data, frequency distribution, mean (standard deviation), variance analysis, and paired samples $t$ tests were used. The results demonstrated a statistically significant difference with mean diaper dermatitis for pretest and posttest group. Apply olive oil was effective on diaper dermatitis than use standard care. Families have to be informed about the importance of a clean and dry diaper area and the frequency of diaper change. The use of olive oil has decreased the incidence of the disease. Olive oil can be an alternative treatment for diaper dermatitis
\end{abstract}

Keywords: Apply Olive Oils, Infant, Toddlers, Diaper Dermatitis

\begin{abstract}
Abstrak
Ruam popok adalah salah satu penyakit kulit yang paling umum dialami oleh bayi dan balitas dengan tingginya angka insidensi dan prevalensi. Ruam popok terjadi karena kurangnya pengetahuan dalam pemberian perawatan pada kulit bayi dan balita. Salah satu perawatan kulit pada bayi dan balita dengan ruam popok adalah pemberian minyak zaitun. Minyak zaitun merupakan suatu herbal yang dapat membantu dengan mempunyai efek anti inflamasi, analgesic, anti-mikroba dan antioksidan. Tujuan pada penelitian ini adalah untuk menganalisis efektivitas pemberian minyak zaitun terhadap ruam popok pada bayi dan balita berusia 0-36 bulan. Jenis penelitia adalah quasi eksperimen dengan desain satu kelompok pretest-posttest pada 40 responden melalui total sampling. Responden diteliti dari bulan Juni sampai Agustus 2019 Instrumen Diaper Dermatitis Severity Index Score digunakan dalam mengukur ruam popok. Untuk menganalisis dan membandingkan data, distribusi frekuensi, mean (standar deviasi), Paired t-test digunakan. Hasil penelitian menunjukkan bahwa adanya perbedaan yang signifikan secara statistik ruam popok pada kelompok pretest dan posttest. Pemberian minyak zaitun efektik terhadap ruam popok dibandingkan dengan perawatan standar. Keluarga diinformasikan tentang pentingnya kebersihan dan keringnya area popok dan frekuensi perubahan popok. Penggunaan minyak zaitun dapat menurunkan insidensi penyakit. Minyak zaitun dapat menjadi pengobatan alternative pada ruam popok.
\end{abstract}

Kata Kunci: Pemberian ruam popok, Bayi, Balita, Ruam popok 


\section{PENDAHULUAN}

Ruam popok merupakan inflamasi kulit yang umum pada area popok untuk bayi dan balita. Hal ini disebabkan oleh terpaparnya urin dan feses pada kulit yang lama (Sikic, Maver, Marcun, \& MiceticTurk, 2018). Ruam popok atau juga diaper rash, berkaitan dengan infeksi. Sejak popok sering digunakan pada balita, banyak komplikasi yang terjadi pada kelompok usia ini (Bonifaz et al., 2016). Hal ini menjadi sebagai salah satu masalah kulit pada bayi dan balita, dengan prevalensi $7 \%$ dan $50 \%$ (Coughlin, Frieden, \& Eichenfield, 2014).

Insidensi dan onset usia yang terkena ruam popok secara global bervariasi, ini berkaitan dengan pengunaan popok, toilet training, kebersihan dalam negara yang berbeda. Prevalensi ruam popok diperkirakan 7-35\% dan insidensi tertinggi antara 9 dan 12 bulan. Penelitian sebelumnya pada 12,103 bayi dan balita di Inggris diidentfikasikan insidensi ruam popok sebesar $25 \%$ selama 4 minggu pertama sejak lahir (Klunk, Domingues, \& Wiss, 2014). The Prevalensi ruam popok yang dijumpai berbeda-beda tiap negara, rentangnya dari $15 \%$ di Italia, $43.8 \%$ di China, $75 \%$ di Amerika Serikat, dan 87\% di Jepang (Hurdoyal \& Pandamikum, 2015). Di Indonesia, hasil laporan tentang angka insidensi ruam popok belum tersedia. Penelitian sebelumnya yang dilakukan di Jakarta, dari 95 responden, 25 responden mempunyai ruam popok atau $26 \%$ dari total sampel (Rustiyaningsih, Rustina, \& Nuraini, 2018). Di Palembang, Penelitian yang dilakukan pada 11 bayi menunjukkan bahwa rata-rata usia bayi adalah 14.73 bulan. Mayoritas jenis kelamin bayi adalah laki-laki (72.7\%) (Cahyati, Indriansari, \& Kusumaningrum, 2015).

Etiologi dari ruam popok mempunyai banyak faktor. Tiga tipe terbanyak ruam popok adalah chafing dermatitis, irritant contact dermatitis, dan diaper candidiasis. Akan tetapi diagnosa diferensial dari ruam popok beragam (Paller \& Mancini, 2016).
Pada pasien mempunyai respons terapi yang lama atau tidak ada, diagnosa alternative sebaiknya ditentukan dan pemeriksaan diagnostic yang sesuai dilakukan. Gambar 1 . meringkas faktor-faktor yang terlibat dalam patofisiologi ruam popok. Ruam popok terjadi ketika paparan lama pada kulit ke faktor-faktor dimana karakteristik area popok termasuk lembab berlebihan, friction, $\mathrm{pH}$ tinggi, dan aktivitas enzim yang tinggi, berhubungan dengan fungsi epidermal (Stamatas \& Tierney, 2014).

Pengobatan konvensional dan phytotherapy dapat menggunakan ekstrak daun zaitun untuk menangani dan mencegah hipertensi arterial atau diuretik dan antiseptik. Beragam penelitian tentang ekstrak daun zaitun yang menunjukkan bahwa dalam menurunakan tekanan darah pada hewan sama seperti untuk meningkatkan aliran darah melalui arteri koronaria, menurunkan denyut jantung, dan menormalkan kontraksi otot usus (GorzynikDebicka et al., 2018). Pada penelitian klinis termasuk pada pasien dengan hipertensi derajat satu dapat ditangani dengan ekstrak daun zaitun, kecenderungan penurunan tekanan darah dapat diobservasi. Sehari dual= kali pada $500 \mathrm{mg}$ (1g/hari) pada ekstrak daun zaitun efektig sebagai pengobatan alternative yang dapat dianjurkan untuk menurunkan tekanan darah.

Ruam akan dikarakteristikkan dengan tampak kasar, lembab, atau adanya macula dan papula pada kulit yang kontak langsung dengan popok. Terutama pada lipatan kulit. Pada beberapa kasus, bayi dan balita yang mengalami ruam akan tampak merah dan berkembang dan meluas. Pustula yang lunak juga sering terjadi. Ketika infeksi Candida albicans terjadi, ruam mempunyai plak merah terang dengan bagian tepi yang tajam akan pecah dan keluar. Papula dan pu stule kecil akan terlihat pada sepanjang lesi. Lipatan kulit akan terpengaruh/terkena (Ball, Bindler, Cowen, \& Shaw, 2017). 


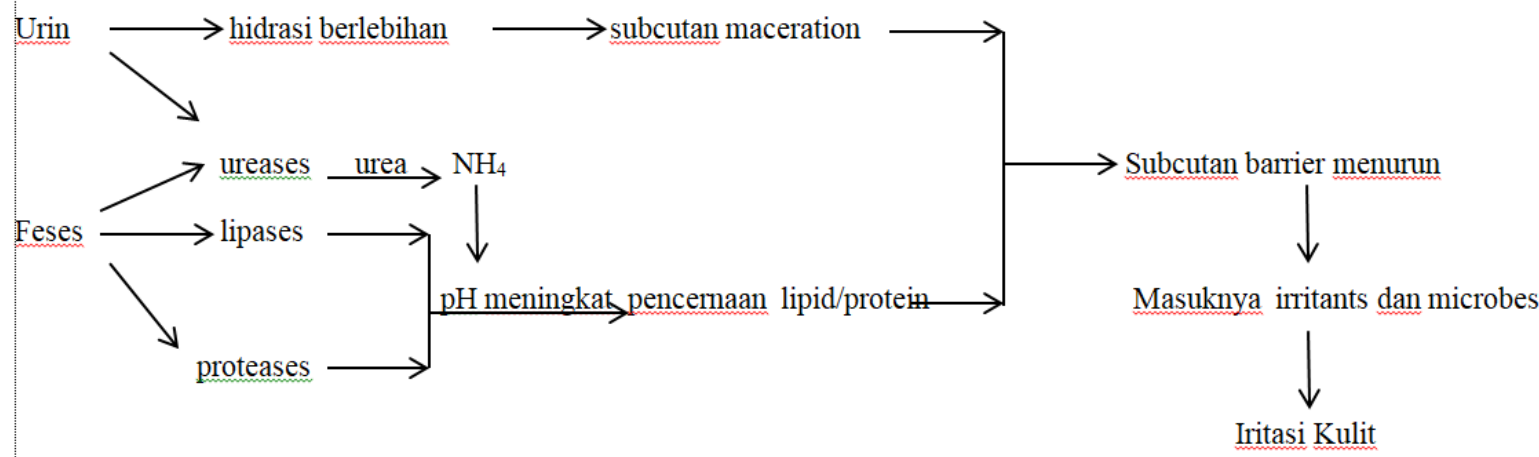

Gambar 1. Faktor fisik dan biokimia terlibat dalam patofisiologi ruam popok

\section{METODE PENELITIAN \\ Desain Penelitian}

Tujuan penelitian ini adalah menganalisis efektivitas pemberian minyak zaitun terhadap ruam popok pada bayi dan balita usia 0 sampai 36 bulan. Jenis penelitian ini adalah quasi eksperimen dengan desain satu kelompok pretest-postest, dimana suatu pilihan yang rasional ketika dampak intervensi yang diharapkan dan hal lain yang menyebabkan sedikit kredibilitas (Polit \& Beck, 2012). Dalam penelitian ini terdiri satu kelompok, sebuah kelompok intervensi yang digunakan minyak zaitun sebagai terapi komplementer sebanyak dua kali sehari.

\section{Sampel}

Empat puluh responden, dimana kelompok intervensi. Kriteria inklusi pada responden: bayi dan balita dengan usia 0-36 bulan, menggunakan popok dengan sering, tidak sedang menggunakan pengobatan medis, tinggal bersama dengan keluarga, dan ibu yang mempunyai anak bersedia menjadi responden. Kriteria eksklusi diantaranya : mempunyai komplikasi penyakit yang serius, mempunyai alergi terutama pada minyak esensial, dan mempunyai luka atau serius pada area kulit.

\section{Instrumen}

DDSIS (Diaper Dermatitis Severity Index Score) diberikan sebelum dan setelah intervensi, dimana pemberian minyak zaitun dua kali sehari. Post-test DDSIS diberikan pada responden ketika setelah penggunaan minyak zaitun selama tujuh hari.

\section{Analisis Data}

Data dianalisis menggunakan komputerisasi. Data dinilai menggunakan mean dan standar deviasi sebagai parametric tests dengan membandingkan nilai DDSIS sebelum dan sesudah intervensi pemberian minyak zaitun. Tes normalitas data menggunakan Kolmogorov-Smirnov, dan paired t-test digunakan untuk menentukan adanya efek pemberian minyak zaitun terhadap ruam popok.

\section{HASIL PENELITIAN}

Empat puluh balita direkrut yang sesuai kriteria inklusi. Tabel 1 menunjukkan karakteristik demografi dan klinis pada responden $\quad(\mathrm{N}=40) \quad$ (semua responden menerima minyak zaitun sebagai intervensi pada ruam popok). Mayoritas ibu mempunyai tingkat pendidikan sekolah menengah atas $(51.4 \%)$, bekerja sebagai wiraswasta $(48.6 \%)$, dengan penghasilan perbulan 1-2 juta rupiah $(77.1 \%)$, dan rata-rata usia ibu adalah 28 tahun selama pengumpulan data. 
Tabel 1. Frekuensi Karakteristik Demografi pada Ibu yang Mempunyai Bayi dan Balita dengan Ruam Popok usia 0 sampai 36 Bulan $(\mathrm{N}=40)$

\begin{tabular}{|l|l}
\hline Karakteristik & $\mathbf{f}(\mathbf{\%})$ \\
\hline Tingkat Pendidikan & \\
Sekolah Dasar & $2(5.7)$ \\
Sekolah Menengah Pertama & $6(14.3)$ \\
Sekolah Menengah Atas & $20(51.4)$ \\
Pendidikan Tinggi & $12(28.6)$ \\
Pekerjaan & \\
Pegawai Negeri Sipil & $5(11.4)$ \\
Wiraswasta & $19(48.6)$ \\
Petani & $13(31.4)$ \\
Pegawai Swasta & $3(8.6)$ \\
Penghasilan per bulan (Rupiah) & $31(77.1)$ \\
1-2 Juta & $9(22.9)$ \\
3-5 Juta & Mean \\
Usia Ibu (Tahun) & 28 \\
\hline
\end{tabular}

Karakteristik bayi dan balita dapat ditunjukkkan pada Tabel 2. Kebanyakan responden berjenis kelamin laki-laki (65.7\%), tidak mempunyai riwayat diare $(68.6 \%)$, tidak mempunyai riwayat ruam popok $(54.3 \%)$, lokasi ruam di area gluteal $(54.3 \%)$, dan rata-rata usia balita adalah 17 bulan.

Tabel 2. Distribusi Frekuensi dan Persentase Karakteristik Demografi dan Klinis pada Bayi dan Balita Usia 0 sampai 36 Bulan

\begin{tabular}{lc}
\hline Karakteristik & $\mathbf{f ( \% )}$ \\
\hline Jenis Kelamin & $26(65.7)$ \\
Laki-laki & $14(34.3)$ \\
Perempuan & $13(31.4)$ \\
Riwayat Diare & $27(68.6)$ \\
Ya & \\
Tidak & $18(45.7)$ \\
Riwayat Ruam Popok & $22(54.3)$ \\
Ya & \\
Tidak & $22(54.3)$ \\
Lokasi Ruam & $18(45.7)$ \\
Gluteal & Mean \\
Perineum & 17 \\
Usia Balita (Bulan)
\end{tabular}

Tabel 3. Distribusi Frekuensi dan Persentase Ruam Popok pada Bayi dan Balita Usia 0 sampai 36 Bulan ( $\mathrm{n}=40)$

\begin{tabular}{|c|c|c|c|c|c|}
\hline \multirow{3}{*}{ Variabel } & \multirow{3}{*}{ Kategori } & \multicolumn{4}{|c|}{ Kelompok } \\
\hline & & \multicolumn{2}{|c|}{ Pre-test } & \multicolumn{2}{|c|}{ Post-test } \\
\hline & & $\mathbf{f}$ & $\%$ & $\mathbf{f}$ & $\%$ \\
\hline \multirow{3}{*}{$\begin{array}{l}\text { Ruam } \\
\text { Popok }\end{array}$} & Ringan & 2 & 2.9 & 25 & 62.9 \\
\hline & Sedang & 22 & 54.3 & 15 & 37.1 \\
\hline & Berat & 17 & 42.9 & 0 & 0.00 \\
\hline
\end{tabular}


Tabel 3 menunjukkan bahwa tingkat sedang pada kelompok post-test sebesat $62.9 \%$ responden mengalami tingkat ringan sebelumnya.

Tabel 4. Mean dan Standar Deviasi Ruam Popok pada Bayi dan Balita Usia 0 sampai 36 Bulan

\begin{tabular}{lcccc}
\hline \multirow{2}{*}{ Variabel } & \multicolumn{2}{c}{ Pre-test } & \multicolumn{2}{c}{ Post-test } \\
\cline { 2 - 5 } & M & SD & M & SD \\
\hline Ruam Popok & 4.46 & 1.19 & 2.14 & 0.84 \\
\hline
\end{tabular}

Mean skor didapatkan dari instrumen diaper dermatitis index score yang ditunjukkan pada Tabel 4. Nilai mean pada saat pre intervensi adalah 4.46 dan menurun menjadi 2.14 setelah tujuh hari dilakukan intervensi.

Tabel 5. Efektivitas Pemberian Minyak Zaitun Terhadap Ruam Popok (n=40)

\begin{tabular}{lccc}
\hline \multirow{2}{*}{ Variabel } & Pre-test & Post-test & \multirow{2}{*}{ p value } \\
\cline { 2 - 3 } & Mean \pm SD & Mean \pm SD & \\
\hline DDSIS & $4.46 \pm 1.19$ & $2.14 \pm 0.84$ & $* 0.000$ \\
\hline
\end{tabular}

Paired t-test $(p<0.05)$

Pada tabel 5 hasil uji paired t-test didapatkan hasil $\mathrm{p}$-value $=0.000$, dimana mengindikasi kan bahwa ada perbedaan yang signifikan antara kelompok pre-test dan posttest terhadap ruam popok pada bayi dan balita usia 0 sampai 36 bulan dengan penilaian Diaper Dermatitis Severity Index Score yang mana mean pada kelompok pretest $(4.46 \mathrm{SD}=1.19)$ lebih besar daripada mean kelompok post-test $(2.14 \mathrm{SD}=0.84)$. ini dapat disimpulkan bahwa nilai DDSIS lebih baik pada post-test dibandingkan pada saat pre-test.

\section{PEMBAHASAN}

Pada penelitian sebelumnya yang menilai efek minyak zaitun terhadap bayi dan balita dengan ruam popok telah melaporkan bahwa pemberian minyak zaitun mempunyai efek yang baik pada skala dermatitis (Cahyati, Idriansari, \& Kusumaningrum, 2015). El Sakka, Abdulrhman, Iman, and Shehata (2013) juga melaporkan bahwa skor gejala secara signifikan menurun pada 3 sampai 5 hari. Sebuah penelitian pada pasien luka tekan oleh Handayani, Irawaty, and Panjaitan (2011) juga menunjukkan bahwa minyak dapat mencegah komplikasi. Temuan dari penelitian ini mengkonfirmasi sejumlah penelitian dan mengindikasikan bahwa pemberian minyak zaitun mempunyai efek yang baik terhadap ruam popok.

Faktor yang berhubungan dengan ruam popok adalah frekuensi buang air besar. Frekuensi defekasi yang lebih besar berhubungan dengan tingginya risiko ruam popok. Frekuensi defekasi yang tinggi akan meningkatkan risiko ruam popok karena ini akan mengacu pada potensi meningkatnya iritasi kulit. Oleh karena itu, neonates dengan frekuensi defekasi yang tinggi membutuh perawatan kulit seperti pergantian popok secara rutin.

Ada perbedaan yang signifikan antara epidermis balita dan orang dewasa, dimana meliputi keratinosit yang lebih kecil, struktur mikrorelief, stratum korneum yang menebal, proliferasi sel yang luas, dan perbedan serat kolagen pada lapisan dermis. Lemak ekstraseluler pada matriks stratum korneum bertindak sebagai pelindung yang mencegah kehilangan air dan masuknya zat hydrophilic seperti air dimana corneocytes memberikan perlindungan mekanik dari lingkungan eksternal (Visscher, 2014).

Manajemen ruam popok mempunyai banyak pendekatan. Akan tetapi, pada diagnosa yang tepat dan pengobatan yang sesuai, tenaga kesehatan sebaiknya mempunyai pengetahuan tentang etiologi ruam popok, fisiologi kulit, dan 
mikrobakterial kulit. Untuk menghilangkan penyebab ruam popok dan menggunakan salep pelindung akan cukup membantu dalam mengobati kasus yang ringan. Akan tetapi, pada pendekatan terapeutik terbaik, pemeriksaan jamur dan bakteri sebaiknya dijalankan ketika ada dugaan (Shin, 2014).

Di samping itu, suatu variasi faktor yang dapat mempengaruhi kerentanan pada iritasi ruam popok atau dapat memperburuk ruam popok untuk mucul. Hal ini meliputi: pergantian popok yang lama, penggunaan antibiotic spectrum luas pada bayi, perawatan kulit yang buruk pada area popok, penggunaan cairan sabun untuk membersihkan kulit, dan menggunakan bedak talcum (Tuzun et al., 2015).

\section{KESIMPULAN}

Temuan penelitian ini memberikan anjuran bahwa pemberian minyak zaitun mempengaruhi ruam popok pada bayi dan balita dan sebaiknya dijadikan sebagai rencana perawatan. Pemberian ruam popok hanya membutuhkan peralatan sederhana dan intervensi dapat dilakukan sehabis bayi dan balita mandi. Penelitian ini juga merekomendasikan pada edukasi keluarga dan secara terjadwal diberikan pada rencana pengobatan pada pasien ruam popok.

\section{REFERENSI}

Ball, J.W., Bindler, R.C., Cowen, K.J., \& Shaw, M.R. (2017). Principles of pediatric nursing: Caring for children. Seventh Edition. New Jersey: Pearson Education.

Blanco, D. \& Rossem, K.V (2013). A prospective two-year assessment of miconazole resistance in Candida spp. With repeated treatment with $0.25 \%$ miconazole nitrate ointment in neonates and infants with moderate to severe diaper dermatitis complicated by cutaneous candidiasis. Pediatric Dermatology, 30 (6), 717-724. doi: 10.1111/pde. 12107

Blume-Peytavi, U., Kanti, V. (2018). Prevention and treatment of diaper dermatitis. Pediatric Dermatology, 35(Suppl 1), s19-s23. doi: 10.1111/pde.13495

Bonifaz, A., Rojas, R., Sanchez, A. T., Lopez, PD. C., Mena, C, Calderon, L, \& Maria, P. O. R. (2016). Superficial mycoses associated with diaper dermatitis. Mycopathologia, 181(9), 671-679. https://doi.org/10.1007/s11046-0160020-9

Cahyati, Idriansari, \& Kusumaningrum. (2015) Pengaruh Virgin Coconut Oil Terhadap Ruam Popok Pada Bayi. Jurnal Keperawatan Universitas Sriwijaya.

Coughlin, C. C., Frieden, I. J., \& Eichenfield, L. F. (2014). Clinical approaches to skin cleansing of the diaper area: Practice and challenges. Pediatric Dermatology, 31(Suppl 1), 1-4. https://doi.org/10.1111/pde.12461

El Sakka, A., Abdulrhman, M., Iman, H., \& Shehata. (2013). 'Comparison between topical application of honey, bees wax and olive oil Propolis extract and nystatin for treatment of diaper dermatitis in Infants'. International Journal of Paediatrics and Child Health, 1(4), 039-042.

Gorzynik-Debicka, M., Przychodzen, P., Cappello, F., Kuban-Jankowska, A., Marino Gammazza, A., Knap, N., Gorska-Ponikowska, M. (2018). Potential health benefits of olive oil and plant polyphenols. International journal of molecular sciences, 19(3), 686.

https://doi.org/10.3390/ijms1903068 6

Handayani, R. S., Irawaty, D., \& Panjaitan, R. U. (2011). Pencegahan luka tekan melalui pijat menggunakan virgin coconut oil. Jurnal Keperawatan Indonesia, 14(3), 141-148. https://doi.org/10.7454/jki.v14i3.60

Hurdoyal, S. D., Pandamikum, L. (2015). A study to investigate the prevalence of nappy rash among infants and toddlers aged 0 to 36 months old in a 
tropical country. Austin of Journal Dermatology, 2(2), 1-3.

Klunk, C., Domingues, E., \& Wiss, K. (2014). An update on diaper dermatitis. Clinics in Dermatology, 32(4), 477-487. https://doi.org/10.1016/j.clindermatol .2014 .02 .003

Paller, A. S. \& Mancini, A. J. (2016). Hurwitz clinical pediatric dermatology : A textbook of skin disoders of childhood and adolescence. 5th Edition. Canada: Elseiver.

Polit, D. F., \& Beck, C. T. (2012). Nursing research: Generating and assessing evidence of nursing practice. Ninth Edition. Philadelphia: Lippincott Williams \& Wilkins.

Rustiyaningsih, A., Rustina, Y., \& Nuraini, T. (2018). Faktor yang berhubungan dengan ruam popok pada bayi baru lahir. Jurnal Persatuan Perawat Nasional Indonesia, 3(2), 58-67 http://dx.doi.org/10.32419/jppni.v3i2 .103

Shin, H.T. (2014). Diagnosis and management of diaper dermatitis. Pediatric Clinic North America, 61(2),367-382. https://doi.org/10.1016/j.pcl.2013.11. 009

Sikic, P. M. , Maver, U., Marcun, V. N. \& Micetic-Turk, D. (2018). Diagnosis and management of diaper dermatitis in infants with emphasis on skin microbiota in the diaper area. International Journal of Dermatology, 57(3), 267-275. https://doi.org/10.1111/ijd.13748

Stamatas, G. N., Tierney, N.K. (2014). Diaper dermatitis: Etiology, manifestations, prevention, and management. Pediatric Dermatology, 31(1):1-

7. https://doi.org/10.1111/pde.12245

Tuzun, Y., Wolf, R., Baglam S., \& Burhan, E. (2015). Diaper (napkin) dermatitis: A fold (intertriginous) dermatosis. Clinics in Dermatology, $33(4)$, 477-482. https://doi.org/10.1016/j.clindermatol .2015 .04 .012

Visscher, M. (2014). A practical method for rapid measurement of skin condition. Newborn and Infant Nursing Reviews, 14(4), 147-152. https://doi.org/10.1053/j.nainr.2014.1 0.002 